\title{
Engajamento e intervenção sonora no Brasil no pós-1964: a ditadura militar e os sentidos plurais do show Opinião ${ }^{1}$
}

\author{
Kátia Rodrigues PARANHOS ${ }^{2}$ \\ Universidade Federal de Uberlândia - UFU
}

\section{Cena I: arte e engajamento}

Teatro popular e teatro engajado são duas denominações que ganharam corpo por intermédio de um vivo debate que atravessou o final do século XIX e se consolidou no século XX. Seu ponto de convergência estava na tessitura das relações entre teatro e política ou mesmo entre teatro e propaganda. Para o crítico inglês Eric Bentley, o teatro político se refere tanto ao texto teatral como a quando, onde e como ele é representado. Aliás, ao saudar a presença do teatro engajado, na década de 1960 nos Estados Unidos, Eric Bentley lembra que o fenômeno teatral por si só é subversivo:

[...] onde quer que 'duas ou três pessoas se reúnem', um golpe é desfechado contra as abstratas não-reuniões do público da TV, bem como contra as reuniões digestivas de comerciantes exaustos na Broadway. [...] A subversão, a rebelião, a revolução no teatro não são uma mera questão de programa, e muito menos podem ser definidas em termos de um gênero particular de peça (BENTLEY, 1969, p. 160 e 178). ${ }^{3}$

Por vezes condenada como escapista, noutras vezes incensada como ferramenta de libertação revolucionária, a arte, de modo geral, continua sendo um tema candente tanto na academia como fora dela. Este trabalho aborda a importância histórica do show Opinião, encenado em dezembro de 1964, por meio das temáticas inseridas em seu roteiro, bem como seu repertório, como uma representação política de resistência à ditadura militar no Brasil. Enfatizo como características fundamentais desse musical a mistura de tradições culturais, a predominância do que Eric Hobsbawm designa "canções funcionais" 4 (canções de trabalho, músicas satíricas e lamentos de amor) e a produção/criação artística dos

\footnotetext{
${ }^{1}$ Este trabalho conta com o apoio financeiro do CNPq (Conselho Nacional de Desenvolvimento Científico e Tecnológico) e da Fapemig (Fundação de Amparo à Pesquisa do Estado de Minas Gerais).

2 Doutora em História Social pela Unicamp. Professora do Instituto de História e do Programa de Pósgraduação em História/Universidade Federal de Uberlândia/UFU. Bolsista produtividade em pesquisa do CNPq e do Programa Pesquisador Mineiro, da Fapemig. Editora de ArtCultura: Revista de História, Cultura e Arte (www.artcultura.inhis.ufu.br).E-mail: katia.paranhos@pq.cnpq.br

3 Para Raymond Williams, o teatro político inclui Piscator e Brecht, sem falar que o teatro da crueldade de Artaud poderia, no limite, ser enquadrado sob essa mesma designação. Sobre o conceito de teatro político, ver Williams (2002, pp. 109-124).

${ }^{4}$ Ver Hobsbawm (1991, p. 52) e Paranhos (2007).
} 
atores/cantores Nara Leão (musa da Bossa Nova), João do Vale (compositor nordestino) e Zé Kéti (sambista carioca). Mas não só a junção de música e teatro tornou o Opinião uma referência. Sua relevância histórica se evidenciou, entre muitos motivos, graças ao momento no qual foi gerado: a estreia do show ocorreu quando o golpe militar ainda não completara um ano de vida e é tida como a primeira grande expressão artística de protesto contra o regime. Também chama atenção a configuração geral do espetáculo que, em forma de arena, não dispunha de cenários, somente de um tablado onde três "atores" encarnavam situações corriqueiras daquele período, como a perseguição aos comunistas, a trágica vida dos nordestinos e a batalha pela ascensão social dos que viviam nas favelas cariocas, tudo isso, acrescente-se, regado a música que visava alfinetar a consciência do público. O repertório, embora fosse assinado por compositores de estilos diversificados, percorria uma linha homogênea de contextos regionais, concedendo-se amplo destaque a gêneros musicais como o baião e o samba. As canções cantadas - por sinal, várias delas marcaram os anos 1960 a ponto de frequentarem inclusive a parada de sucesso exprimiam uma fala alternativa e ilustrativa no musical. Em Borandá, de Edu Lobo, Nara Leão fazia ressoar, com sua voz melancólica, a tristeza dos retirantes que, impelidos pela seca, eram obrigados a abandonar a zona rural nordestina. Já em Carcará, a composição mais emblemática do negro maranhense João do Vale, a mesma intérprete desfiava a história dessa ave sertaneja, apelando para metáforas sobre sua valentia e coragem. Nessa canção era possível perceber a relação que se estabelecia entre o carcará e a ditadura militar, que investia com toda fúria contra os que a ela se opunham. Daí o interesse em analisar a junção da música e do teatro como expressões de engajamento e de intervenção sonora que fluíam no espetáculo e para fora dele nos tempos difíceis da ditadura militar brasileira, que ainda mostraria fôlego para perdurar, com maior ou menor força, por longos 21 anos.

Cena II: "podem me prender/podem me bater/podem até deixar-me sem comer/que eu não mudo de opinião"

Após o golpe militar de 1964, o grupo de artistas ligados ao Centro Popular de Cultura/CPC (posto na ilegalidade), reuniu-se com o intuito de criar um foco de resistência e de protesto àquela situação. Foi então produzido o espetáculo musical Opinião, com Zé Kéti, João do Vale e Nara Leão (depois substituída por Maria Bethânia), cabendo a direção a Augusto Boal. O espetáculo, apresentado no Rio de Janeiro em 11 de dezembro de 1964, no Teatro Super Shopping Center, marcou o nascimento do grupo e do espaço teatral que 
veio a se chamar Opinião ${ }^{5}$. Os integrantes do núcleo permanente eram Oduvaldo Vianna Filho (o Vianninha), Paulo Pontes, Armando Costa, João das Neves, Ferreira Gullar, Thereza Aragão, Denoy de Oliveira e Pichin Plá.

O show foi organizado no famoso Zicartola - restaurante do sambista e compositor Cartola e de sua companheira Zica -, onde ocorriam reuniões de músicos, artistas, estudantes e intelectuais ${ }^{6}$. Foi esse o ambiente catalisador da união de interesses de experientes dramaturgos e músicos, com diferentes estilos e atuações no campo cultural, que resultou num roteiro inédito: um espetáculo musical que continha testemunhos, música popular, participação do público, apresentação de dados e referências históricas, enfim, um mosaico de "canções funcionais" e de tradições culturais. Tanto o enredo quanto o elenco eram notadamente heterogêneos e talvez seja esse o motivo pelo qual o Opinião tenha começado sua trajetória com sucesso. O grupo privilegiou, desde a estreia, a forma do teatro de revista, numa mescla de apropriações e ressignificações do "popular" e do "nacional", abrindo igualmente espaço para apresentações com compositores de escolas de samba cariocas.

João das Neves, que dirigiu o Opinião por dezesseis anos, enfatiza:

O nosso trabalho era fundamentalmente político e, assim, pesquisar formas nos interessava - e interessa - muito. [...] A busca em arte não é apenas estética - ela é estética e ética ao mesmo tempo. Eu coloco no que faço tudo o que eu sou, tudo o que penso do mundo, tudo o que imagino da possibilidade de transformar o mundo, de transformar as pessoas. Acredito na possibilidade da arte para transformar. Se não fosse assim, eu não faria arte; faria outra coisa (NEVES, 1987, p. 21)7.

Podemos afirmar que o espetáculo não só focalizava como mistificava "novos lugares da memória: o morro (favela + miséria + periferia dos grandes centros urbanos industrializados) e o sertão (populações famintas, [...] o messianismo religioso [...] e o [...] coronelismo)" (CONTIER, 1998, p. 20). Por meio da música, as interpretações e discussões a respeito dessas realidades fluíam no espetáculo, alternadas por depoimentos

\footnotetext{
${ }^{5}$ De acordo com João das Neves (2010), o nome Grupo Opinião passou a ser utilizado a partir da encenação de Se correr o bicho pega, se ficar o bicho come, em 1966.

${ }^{6}$ Ver Castro (2004).

7 É importante salientar que o grupo Opinião focalizava suas ações no teatro de protesto, de resistência, e também se caracterizava por ser um centro de estudos e de difusão da dramaturgia nacional e popular. Afinado com essas propostas artísticas e ideológicas, o diretor João das Neves privilegiava a montagem de textos, tanto nacionais quanto estrangeiros, que servissem de enfoque para a situação política do Brasil nos anos da ditadura, tais como: A saída, onde fica a saída?, em 1967, de Armando Costa, Antônio Carlos Fontoura e Ferreira Gullar; Jornada de um imbecil até o entendimento, em 1968, de Plínio Marcos; Antígona, em 1969, de Sófocles, numa tradução de Ferreira Gullar; A ponte sobre o pântano, em 1971, de Aldomar Conrado; O último carro, em 1976, Mural mulher, em 1979, e Café da manhã, em 1980, de João das Neves. Ver Neves (1987).
} 
dos atores que compartilhavam, fora do palco, as mesmas dificuldades cantadas por eles, como nos casos de João do Vale (nordestino retirante) e Zé Kéti (morador de uma favela carioca). Já Nara Leão - conhecida como a musa da bossa nova que personalizava a classe média - assumia uma postura de engajamento e se posicionava de forma ativa e questionadora da realidade brasileira.

Recorto aqui alguns trechos do show ${ }^{8}$ :

Minha terra tem muita coisa engraçada, mas o que tem mais é muita dificuldade pra viver (João do Vale. In: COSTA, 1965, p. 19).

Vida de sambista vou te contar. Passei oito anos em estúdio de rádio, atrás de cantor, até conseguir gravar minha primeira música. O samba - 'A voz do morro' - eu sou o samba (...). Aí ele teve mais de 30 gravações. (...) O dinheiro que ganhei deu para comprar uns móveis de quarto estilo francês e comi três meses carne (Zé Kéti. In: Idem, p. 19).

Ando muito confusa sobre as coisas que devem ser feitas na música brasileira mas vou fazendo. Mas é mais ou menos isso - eu quero cantar todas as músicas que ajudem a gente a ser mais brasileiro, que façam todo mundo querer ser mais livre, que ensinem a aceitar tudo, menos o que pode ser mudado (Nara Leão In: Idem, p. 20).

Esse movimento de aproximação das diferenças num palco de teatro foi conduzido por uma tendência ainda de caráter cepecista, uma vez que nos CPCs o principal lema era portar-se como transmissor de uma mentalidade revolucionária para o povo e assim atingir a tão utópica revolução social ${ }^{9}$. Não poderia ser diferente, pois os dramaturgos do Opinião, como Vianninha e o poeta Ferreira Gullar, eram membros ativos dos Centros Populares de Cultura e utilizavam suas peças, inclusive o musical Opinião, como meio de "fazer emergir" na plateia "valores novos" e uma "capacidade mais rica" de sentir a "realidade" (KÜHNER e ROCHA, 2001, p. 54-55) ${ }^{10}$ no intuito de estabelecer uma identificação entre os atores e o público. Segundo Heloísa Buarque de Hollanda e Marcos Gonçalves (1995, pp. 23-4), "encenava-se um pouco da ilusão que restara do projeto político-cultural pré-64 e que a realidade não parecia disposta a permitir: a aliança do povo com o intelectual, o sonho da revolução nacional e popular”.

Como já mencionado anteriormente, a estrutura geral do espetáculo era em forma de arena, não dispunha de cenários; tinha somente um tablado no qual os três "atores", em seus trajes cotidianos (camiseta e jeans), falavam de si, de sua vida, de suas lembranças e cantavam e encenavam situações daquele período. Vejamos alguns exemplos:

\footnotetext{
${ }^{8}$ Ver também o CD Grupo Opinião (1994).

${ }^{9}$ Sobre a noção de "povo" para os integrantes do CPC, ver Mostaço (1982, especialmente, pp. 59-60).

${ }^{10}$ Mais detalhes da atuação do CPC no Rio de Janeiro, ver Neves (1987). 
1. sobre a seca

Já fiz mais de mil promessas

Rezei tanta oração

Deve ser que eu rezo baixo

Pois meu Deus não me ouve, não (Borandá, Edu Lobo. In: Idem, p. 28).

2. a condição do nordestino retirante, no olhar de Zé Kéti

O morro sorri mas chora por dentro

Quem vê o morro sorrir

Pensa que ele é feliz

Coitado

O morro tem sede

O morro tem fome

O morro sou eu

Um favelado (Favelado, Zé Kéti. In: Idem, p. 29).

3. a questão da terra

Eu sou um pobre caboclo

Ganho a vida na enxada

O que colho é dividido

Com quem não plantou nada

Se assim continuar

Vou deixar o meu sertão

Mesmo com os olhos cheios d'água

E com dor no coração (Missa agrária, Carlos Lyra e G. Guarnieri. In: Idem, p. 44).

4. a esperança no futuro

E no entanto é preciso cantar

Mais do que nunca é preciso cantar

É preciso cantar e alegrar a cidade

A tristeza que a gente tem

Qualquer dia vai se acabar (Quarta-feira de cinzas, Vinicius de Moraes e Carlos Lyra. In: Idem, p. 61)

Eu sou o samba

A voz do morro sou eu mesmo, sim senhor

Quero mostrar ao mundo que tenho valor

Eu sou o rei dos terreiros.... (A voz do morro, Zé Kéti. In: Idem, p. 78).

Incluir o(s) marginalizado(s) na cena teatral brasileira não foi um mérito exclusivo do show. Basta lembrar de Eles não usam black-tie de Gianfrancesco Guarnieri ${ }^{11}$. Contudo, o formato musical e o roteiro não cronológico diferenciavam o show pela aproximação que esses elementos propiciavam entre palco e plateia. Como decorrência de toda a sua

\footnotetext{
11 Segundo Costa (1996, p. 21) "a novidade era que Black-tie introduzia uma importante mudança de foco em nossa dramaturgia: pela primeira vez o proletariado como classe assume a condição de protagonista de um espetáculo".
} 
concepção, o show Opinião se calcava no pressuposto de que a representação da realidade se alinha com a perspectiva de "teatro verdade" e implica a criação de um ambiente de comunhão e igualdade entre todas as partes envolvidas no espetáculo, sobretudo o público, como se todos tivessem um denominador comum: estariam irmanados por pertencerem, de maneira inescapável, à mesma realidade.

Aliás, é interessante mencionar que o Opinião

atraiu basicamente estudantes e pessoas do mundo artístico, apesar de seu público variar de estudantes a classe média alta. Entretanto, o número de espectadores que viram o espetáculo dá uma ideia mais ampla de sua recepção. Ross Butler conta que em algumas semanas mais de 25 mil pessoas o tinham visto no Rio, e que em São Paulo e Porto Alegre (onde foi encenado mais tarde) mais de cem mil pessoas o assistiram. O espetáculo teve também um efeito multiplicado: Opinião se tornou emblemático de protesto e solidariedade para muitos outros que não viram o show mas, tendo ouvido falar dele, compraram o disco (DAMASCENO, 1994, p. 169) $)^{12}$.

Podemos ainda registrar sobre o show a variedade de temas, de ritmo, de músicas, a imprevisibilidade da ação cênica, a troca entre as diferentes dimensões - a poética, a política, a ética, a história - dos testemunhos que vão se desdobrando em atos performáticos, em discursos de caráter multitemático, caleidoscópicos por assim dizer. Vale a pena retomar alguns trechos de duas músicas do espetáculo, que em especial empolgavam a plateia que superlotava o teatro naquelas noites sombrias. Na primeira, Opinião, Zé Kéti cantava: "Podem me prender/Podem me bater/Podem até deixar-me sem comer/Que eu não mudo de opinião". Na segunda, Carcará, pela voz de Nara Leão, João do Vale narrava as aventuras de um pássaro voraz do sertão, que não morre porque, com seu bico volteado que nem gavião, "pega, mata e come" (COSTA, 1965, pp. 41 e 62).

Em artigo de 1968, Dias Gomes declara:

Toda arte é, portanto, política. A diferença é que, no teatro, esse ato é praticado diante do público. [...] o teatro é a única arte [...] que usa a criatura humana como meio de expressão. [...] Este caráter de ato político-social da representação teatral, ato que se realiza naquele momento e com a participação do público, não pode ser esquecido se quisermos entender por que coube ao teatro um papel destacado na luta contra o status quo implantado em abril de 64 (GOMES, 1968, p. 10).

Convém registrar que, no entendimento de Gomes, desde Anchieta - "nosso primeiro dramaturgo [e] também o nosso primeiro autor político"(GOMES, 1968, p. 10) -, teatro e política estão umbilicalmente ligados à questão da função social da arte. A defesa

12 Vale conferir uma visão crítica sobre o show Opinião entendido como uma das "criações de um grupo de classe média para consumo das próprias ilusões" Tinhorão (1997, p. 86). 
do engajamento, portanto, parte do princípio de que os autores que falam sobre a realidade brasileira (sob diferentes óticas) são engajados. Isso significa dizer que o teatro é uma forma de conhecimento da sociedade. Assim, mesmo quem se autoproclama não engajado ou apolítico, na verdade, assume uma posição, também, política.

Por sinal, ao se referir aos diferentes gêneros literários, Benoît Denis (2002, p. 83) salienta que o teatro é um "lugar" importante do engajamento; é exatamente aquele que propicia as formas mais diretas de interação entre escritor e público: “através da representação teatral, as relações entre o autor e o público se estabelecem como num tempo real, num tipo de imediatidade de troca, um pouco ao modo pelo qual um orador galvaniza a sua audiência ou a engaja na causa que defende".

O sentimento de transformação política está presente em todo o corpo da peça. Suas origens musicais, o passado dos integrantes no cenário de oposição e intervenção política, bem como as particularidades dos atores estreantes, tornam-se intrigantes peças de um complexo quebra-cabeças que faz desse espetáculo uma importante referência na trajetória engajada do teatro brasileiro. Para Dias Gomes (1968, p. 11), "a plateia que ia assistir ao show Opinião, por exemplo, saía com a sensação de ter 'participado' de um ato contra o governo" ${ }^{13}$.

A respeito disso, anos depois, comenta Augusto Boal (2000, p. 226):

Eu queria que escutassem não apenas a música, mas a ideia que se vestia de música! Opinião não seria um show a mais. Seria o primeiro show de uma nova fase. Show contra a ditadura, show-teatro. Grito, explosão. Protesto. Música só não bastava. Música ideia, combate, eu buscava: música corpo, cabeça, coração! Falando do momento, instante!

Cabe registrar que vários autores preocupados com a situação pós-golpe abrem discussões acerca da importância do teatro, dos dramaturgos e atores que foram personagens ativos desse período de repressão. Entre eles podemos citar Maria Helena Kühner e Helena Rocha, que trabalham a formação do Grupo de Teatro Opinião (e o show inaugural) como referência de postura política no início do governo militar. $\mathrm{Na}$ leitura da análise por elas desenvolvida é possível vislumbrar, na constituição do Opinião, uma

\footnotetext{
${ }^{13}$ O show, porém, não foi unanimidade de crítica. Por exemplo, nas páginas da Revista Civilização Brasileira, o jornalista e crítico de teatro Paulo Francis observava que "qualquer protesto é útil [...] pois, desde $1^{\circ}$ de abril, o país parece imerso em catatonia, precisando de ser sacudido. Mas Opinião, quando chega ao público, pelos intérpretes e a música, nada contém de indutivo à ação política. Basta-se a si próprio, é muito agradável [...]. Mas daí a considerá-lo como um evento político vai uma certa distância, pois, nesse terreno, o espetáculo nunca sai do Kindergarten sentimental da esquerda brasileira" (FRANCIS, 1965, p. 217).
} 
expressão de urgência de mudança almejada por um grupo que muitos qualificavam de “idealistas, utópicos, românticos, ingênuos, loucos [...] que viveram a geração da utopia” (KÜHNER; ROCHA, 2001, pp. 34-5) e que nela criavam e se apoiavam, a fim de fazer do musical a primeira manifestação de engajamento do teatro brasileiro após a ditadura.

Um exemplo disso era a utilização das músicas, tão presentes, na constituição do show Opinião. O conteúdo das suas representações transita entre o público e o privado, mostrando as mazelas da vida individual do trabalhador e do ambiente ao seu redor. Uma vez identificada essa fagulha de inconformismo, o público do teatro, ali, diante do palco, tem a oportunidade de "retomar a posse de si mesmo, de reencontrar o próprio nome ("Eu sou'), de situar-se no plano social”' (Idem, p. 69).

Por intermédio desse acontecimento cênico se visualiza um leque de representações. O teatro, portanto, passa a se caracterizar não somente como meio de encenação/interpretação, mas também como divulgador de lugares e sentidos políticoculturais.

O show e o grupo Opinião podem ser vistos como exemplos do teatro engajado. Por isso mesmo, representam objetos de interessantes investigações históricas por formular uma voz de protesto inicial, ainda em 1964, configurando-se "como um protesto suprindo uma falta de algo: a possibilidade de dizer. Um protesto, sim, ainda que sob a forma espontânea, simples e improvisada de uma opinião" (Idem, p. 46). Podemos ainda destacar a riqueza de ideias, a fórmula da colagem, a participação do público, a reafirmação da resistência, a valorização das práticas culturais populares, a cumplicidade palco-plateia, a temática ligada à realidade brasileira, a concepção multifacetada de gêneros musicais. Se, como aponta Edelcio Mostaço (1982, p. 61), de um lado a encenação exercitava "uma comunicação de circuito fechado: palco e plateia irmanados na mesma fé", por outro, na mesma medida para Marcos Napolitano (2001, p. 75) representava "a ampliação e a massificação do público, bases fundamentais para entender a entrada dos produtores culturais de esquerda na indústria cultural". ${ }^{14}$

Apesar da censura e da ditadura militar, o teatro brasileiro, nos anos 1960 e 1970, continuará dando sinais de uma produção crescente e voltada, na maioria das vezes, para o campo político. Cabe realçar a atuação dos dramaturgos Jorge Andrade, Gianfrancesco Guarnieri, Augusto Boal, Dias Gomes, Ferreira Gullar, Oduvaldo Vianna Filho, Plínio

${ }^{14}$ Depois da montagem de Antígona, em 1969, o Grupo Opinião, afogado em dívidas, dissolve-se. João das Neves, o único que não aceita tal decisão, decide continuar sozinho e parte em busca de novos parceiros. O teatro inclusive será alugado, em alguns momentos, para jovens iniciantes e o próprio diretor passa a comandar espetáculos fora do eixo Rio-São Paulo. Ver Neves (1984, p. 5559) e Kühner e Rocha (2001). 
Marcos, Carlos Queiroz Telles. Merecem também registro produções teatrais que traziam consigo a insatisfação com a ordem existente, como as do Teatro Universitário (TUCA/PUC-SP, TUSP/USP, TEMA/Teatro Mackenzie) e dos grupos Teatro Jovem (RJ), Teatro Carioca de Arte (RJ), Dzi Croquettes (RJ), Asdrúbal Trouxe o Trombone (RJ), Teatro de Arena de Porto Alegre/TAPA (RS), Grita (CE), Imbuaça (SE), Sociedade Teatro dos Novos (BA), Teatro Livre da Bahia (BA), Oi Nóis Aqui Traveiz (RS). No início da década de 1980, novas companhias despontavam no cenário ainda governado pelos militares, como o Tá na Rua (RJ) e o Galpão $(M G)^{15}$. Nessa perspectiva, os grupos de teatro integram um conjunto significativo de documentos inseridos em certo contexto sócio-histórico e que se constituem como fragmentos de um período e uma forma interpretativa do social.

Para terminar, retomo uma passagem, que considero uma síntese de procedimentos artísticos, de Maria Helena Kühner e Helena Rocha (2001, p. 72):

Opinião foi a primeira aula dada ao público sobre como reaprender a ler certas obras de arte - ensinamento extremamente útil nos anos (de censura) que se seguiram. $\mathrm{O}$ clima, na plateia compacta, ensopada de suor e envolvida pelas paredes de concreto do teatro, era de catarse e sublimação. Vivia-se a sensação de uma vitória que tinha sido impossível lá fora.

\section{BIBLIOGRAFIA CITADA:}

BENTLEY, Eric. O teatro engajado. Tradução de Yan Michalski. Rio de Janeiro, Zahar, 1969.

BOAL, Augusto. Hamlet e o filho do padeiro. Rio de Janeiro, Record, 2000.

CASTRO, Maurício Barros de. Zicartola. Rio de Janeiro, Relume Dumará/Prefeitura, 2004.

CONTIER, Arnaldo Daraya. Edu Lobo e Carlos Lyra: o nacional e o popular na canção de protesto (os anos 60). In: Revista Brasileira de História, v. 18, n. 35, 1998, p. 74-84.

COSTA, Armando et al. Opinião: texto completo do show. Rio de Janeiro, Edições do Val, 1965.

COSTA, Iná Camargo. A bora do teatro épico no Brasil. Rio de Janeiro, Graal, 1996.

DAMASCENO, Leslie Hawkins. Espaço cultural e convençôes teatrais na obra de Odwaldo Vianna Filho. Tradução de Iná Camargo Costa, Campinas, Editora da Unicamp, 1994.

DENIS, Benoît. Literatura e engajamento. Tradução de Luiz Dagobert de Aguirra Roncari. Bauru, Edusc, 2002.

FERNANDES, Sílvia. Grupos teatrais - anos 70. Campinas, Editora da Unicamp, 2000.

FRANCIS, Paulo. Novo rumo para autores. In: Revista Civilização Brasileira, n. 1, Rio de Janeiro, Civilização Brasileira, 1965, p. 215-261.

GOMES, Dias. O engajamento é uma prática de liberdade. In: Revista Civilização Brasileira, Caderno Especial, n. 2, 1968, p. 07-18.

HOBSBAWM, Eric J. História social do jazz: Tradução de Angela Noronha. 2. ed. Rio de Janeiro, Paz e Terra, 1991.

HOLLANDA, Heloísa Buarque de; GONÇALVES, Marcos A. Cultura e participação nos anos 60. 10. ed. São Paulo, Brasiliense, 1995.

${ }^{15}$ Ver Pacheco (1986, p. 95-105), Fernandes (2000) e Paranhos (2009, p. 93-117). 
KÜHNER, Maria Helena; ROCHA, Helena. Opinião: para ter opinião. Rio de Janeiro, Relumé Dumará/Prefeitura, 2001.

NAPOLITANO, Marcos. "Seguindo a canção": engajamento político e indústria cultural na MPB (1959-1969). São Paulo, Annablume/Fapesp, 2001.

PACHECO, Tânia. Teatro alternativo em 70: a luz no final do túnel. In: MELLO, Maria Amélia (org.). Vinte anos de resistência. Rio de Janeiro, Espaço e Tempo, 1986, p. 95-105.

PARANHOS, Kátia Rodrigues. Os festivais de música dos trabalhadores do ABC paulista: tradições culturais, canções e vozes do Brasil. Actas del VII Congreso de la LASPM-AL, 2007. Disponível em < http://www.hist.puc.cl/historia/iaspm/actas.html>.

Textos, espaços e sujeitos sociais: outras linguagens na cena teatral brasileira. In: CARREIRA, André; LIMA, Evelyn Furquim Werneck (orgs.). Estudos teatrais. Florianópolis, Ed. da Udesc, 2009, p. 93-117.

MOSTAÇO, Edelcio. Teatro e politica: Arena, Oficina e Opinião. São Paulo, Proposta Editorial, 1982.

NEVES, João das. Grupo Opinião: a trajetória de uma rebeldia cultural. Problemas, n. 9, São Paulo, Novos Rumos, 1984, p. 55-59.

1987. João das Neves: ciclo de palestras sobre o teatro brasileiro, 5, Rio de Janeiro, Inacen,

A hora do teatro épico. Traulito, n. 3, 2010. Disponível em $<$ http:/ / www.traulito.com.br/?p=808>.

TINHORÃO, José Ramos. Um equívoco de "Opinião". In: Música popular: um tema em debate. São Paulo, Ed. 34, 1987, p. 34-47.

WILLIAMS, Raymond. El teatro como foro político. In: La política del modernismo. Tradução de Horacio Pons. Buenos Aires, Manantial, 2002.

\title{
REFERÊNCIAS DISCOGRÁFICAS:
}

GRUPO OPINIÃO. Show Opinião, Rio de Janeiro, PolyGram, 1994.

\begin{abstract}
This paper deals with the historical relevance of Opinião, a play enacted in December 1964, which had an important role as a political representation of the resistance to the military dictatorship in Brazil. I highlight some key aspects of this musical, such as the mixture of cultural traditions, the predominance of what Eric Hobsbawm names "functional songs" (labor songs, satirical music and love regrets) as well as the art production/creation of actors/singers Nara Leão (a Bossa Nova diva), João do Vale (a Northeastern composer) and Zé Keti (a Rio de Janeiro samba composer).
\end{abstract}

Keywords: Opinião; post-1964 Brazil; engaged play. 